\title{
Stacey FD, Hodgkinson JH: The Earth as a cradle for life-the origin, evolution and future of the environment
}

\author{
Anne Marie de Grosbois
}

(c) Springer-Verlag Berlin Heidelberg 2015

\section{3 | World Scientific Publishing, New Jersey, London | 308 pp | Hardback 978-981-4508-32-2 USD 70.00 GBP 46.00 | eBook ISBN 978-981-4508-35-3 USD 53.00; GBP 35.00}

The book, The Earth as a Cradle for Life-The Origin, Evolution and Future of the Environment, is written by physicist Frank D. Stacey and geologist Jane H. Hodgkinson, who are both from Australia's national science agency, CSIRO. The authors describe their main objective in writing this as "to step back from the immediate problems that are addressed in most environmental discussions and take a long term view of the Earth as the nursery in which life developed over billions of years". With this in mind, the book's first section focuses on the physical framework and astronomical foundations of the Earth. The first four chapters provide a readily comprehensible overview on the various estimations of the Earth's age, its beginnings of life, its rotation, tides, the influence of the moon, sun, and other astronomical effects on the Earth, as well as planetary magnetic fields.

In a straightforward manner, the following eight chapters encapsulate the diverse central aspects underlining planet Earth's development over billions of years. This is obviously a concise but not an exhaustive work. With each chapter, the authors provide a summation of our current understanding on the internal heat and evolution of the Earth, the oceans, planetary atmospheres, the appearance of free oxygen, thermal balance, greenhouse effect, sea level, environmental crises, mass extinctions of species, stability of the environment, inorganic mineral deposits as products of an evolving environment, fossil fuels, buried carbon, and photosynthetic oxygen. The chapters are divided into short sections and an appendix of brief notes is included at the end.

In the final chapters, this long-term view helps in recognizing the significance of the authors' standpoint on the human influences on the environment. The effects of fossil fuel and human energy use are examined. Throughout the book and in Chapter 15 entitled "The cradle is rocking" the time scales of the Earth are emphasized in all issues. While pointing out that the Earth can sustain life for many millions of years, Stacey and Hodgkinson stress that it is evident that the burning of fossil fuel is irreversibly altering the environment. Based on the prominent points and questions in each chapter, the book concludes with a concise list of "salient conclusions". By itemizing the most important points at the end, the deliberate simplification serves for emphasis and as a useful starting point for discussion about the very gradual response by the Earth system to the rapid changes made by humans. Their abridged discussion and appraisal of planet Earth and of its resilience reveal some still unanswered questions about our environment. The book targets undergraduate students from all areas of study and anyone interested in the future of the planet.

A. M. de Grosbois ( $\square$ )

Environmental Earth Sciences, Freiberg, Germany

e-mail: degrosbois@blue-cable.de 